\title{
Is the number of lymph nodes retrieved in laparoscopic colorectal cancer resections related to the learning curve of the surgeon?
}

\author{
O. Aly ${ }^{1}$, E MacDonald ${ }^{2}$, C Watkins ${ }^{2}$, G I Murray ${ }^{3}$, E H Aly ${ }^{2}$ \\ 1. University of Aberdeen. 2. Department of Surgery, Aberdeen Royal Infirmary. 3. Department of Pathology, University \\ of Aberdeen.
}

Correspondence: Emad H Aly. Address: Consultant Surgeon, Laparoscopic Colorectal Surgery \& Training Unit, Aberdeen Royal Infirmary-Aberdeen-Scotland-AB25 2ZN. Telephone: 44-786-0454-176. Email: emad.aly@nhs.net.

Received: August 28, 2011 Accepted: November 10, $201 \quad$ Published: February 1, 2012

DOI : 10.5430/jst.v2n1p16 URL: http://dx.doi.org/10.5430/jst.v2n1p16

\section{Abstract}

Objectives: To find out if the number of lymph nodes retrieved in laparoscopic colorectal cancer surgery is affected by the surgeon's learning curve. Laparoscopic colorectal resections for malignant tumors by experienced laparoscopic surgeons achieve similar oncologic outcomes as open surgery. However, there is currently no data on lymph node retrieval in the early phase of the learning curve of colorectal laparoscopic surgery compared to open surgery.

Methods: Retrospective study of the first 25 colorectal laparoscopic resections (LR) for cancer performed by a single surgeon were compared with his most recent 25 open resections (OR). The same group of pathologists examined \& reported all the resections. The total number of lymph nodes identified within the specimen was compared.

Results: For all resections the median lymph node count was equal for both open and laparoscopic groups. There was no significant difference in lymph node retrieval between the two groups for all resections.

Conclusion: The number of lymph nodes retrieved for colorectal cancer does not seem to be affected by the early part of the learning curve of laparoscopic colorectal surgery. Further studies looking at the results of multiple surgeons are needed to confirm this observation.

\section{Key words}

Lymph nodes, Laparoscopic colorectal cancer, Malignant tumors, Lymph node retrieval

\section{I ntroduction}

Since the first laparoscopic colectomy in $1991^{[1]}$, there have been concerns regarding the oncological outcome and safety of laparoscopic colorectal surgery for malignant disease. Subsequent studies have shown that laparoscopic colorectal procedures by experienced laparoscopic surgeons achieve similar oncologic outcomes as open surgery ${ }^{[2-5]}$. However, the surgeon's training and experience has shown to be an important prognostic factor for survival and local recurrence ${ }^{[6]}$. Furthermore it is known that laparoscopic colorectal surgery has a steep learning curve ${ }^{[7-10]}$. Previous attempts at defining 
the length of the learning curve of laparoscopic colorectal surgery have been based on: operating time, conversion rate, intra-operative, post-operative complications and hospital stay, with results ranging from 30 to 62 cases ${ }^{[7]}$.There is currently no data on lymph node retrieval in the early phase of the learning curve of colorectal laparoscopic surgery compared to open surgery.

\section{Aim}

This study aimed to find out if the number of lymph nodes retrieved by laparoscopic colorectal cancer surgery is affected by the surgeon's learning curve.

\section{Method}

This was a retrospective study of consecutive series of patients, who had underwent open or laparoscopic colorectal surgery for a histologically proven adenocarcinoma of the colon and rectum at Laparoscopic Colorectal Surgery \& Training Unit; Aberdeen Royal Infirmary; Scotland. We compared the first 25 laparoscopic colorectal cancer resections performed by a single consultant surgeon with his most recent 25 open procedures. The total number of lymph nodes identified within the specimen was obtained from the histology report for each patient. Using the histology reports combined with the patient notes the following information was recorded for each patient: age, sex, operation type, Dukes stage and use of preoperative radio-chemotherapy.

This study included the first unsupervised 25 laparoscopic colorectal cancer resections for the senior author. The total number of the various laparoscopic resections was chosen to be kept at 25 cases to make sure that this represents the early learning curve of the surgeon. Cases were selected as appropriate for laparoscopic surgery following diagnosis by endoscopy, biopsy and staging CT of the abdomen \& pelvis. Rectal tumors were also staged by MRI scanning to determine if preoperative chemo/radiotherapy was needed. All cases were discussed in the local MDT meeting \& management plan was agreed.

\section{Surgical technique}

The technique of laparoscopic resection for colonic and rectal tumors has been well described elsewhere ${ }^{[11]}$ and our technique follows these principles with medial to lateral approach in all resections. The specimen for all colorectal cancer resections were sent to the pathology department fresh for processing. Pathology result was then discussed in the local MDT meeting.

We counted all procedures as laparoscopic provided the vessel division and thus the dissection of the apical node was performed laparoscopically. Cases converted early prior to vessel division, for example due to the presence of severe adhesions, are excluded \& not included as either laparoscopic or open cases.

\section{Histological technique}

The colorectal cancers were reported according to the guidelines of the Royal College of Pathologists ${ }^{[12-13]}$. The same group of pathologists examined \& reported both open and laparoscopic procedures in the Pathology Department, Aberdeen Royal Infirmary. Data collected included: histological diagnosis, Dukes' stage, and the number \& lymph node status.

\section{Statistical analysis}

The median number of lymph nodes retrieved was compared between laparoscopic and open procedures to identify if the early learning curve has an effect on the oncological quality of the resection. Further subgroup analysis was done between laparoscopic and open right hemicolectomy and laparoscopic and open anterior resection as there was sufficient numbers 
to allow meaningful comparison. The patients' characteristics such as distribution of the patients' Duke's stage in the open and laparoscopic groups was compared using the Chi Square Test of Independence. Median lymph node counts were compared using the Mann Whitney U test. $P$-values less than or equal to 0.05 were considered statistically significant.

\section{Results}

A total of 50 colorectal cancer resections were identified (Table 1). In order to provide comparison the most recent 25 open colorectal cancer resections were reviewed. The age of the patients ranged from 44 to 85 and 43 to 85 for the open ad laparoscopic groups respectively. The median age of the patients was 70 in both the laparoscopic and open surgery groups, with no significant age difference between the two groups $(p=0.54)$. Overall there were a greater number of males undergoing colorectal surgery (72\%), $80 \%$ in the open group and 64\% in the laparoscopic group. However, there was no significant difference in the sex of patients between the laparoscopic or open group $(p=0.21)$.

There were no significant differences between the Dukes staging in the laproscopic and open surgery groups $(p=0.33)$ for all resections, right hemicolectomies $(p=0.92)$ and anterior resections $(p=0.12)$ (Table 2).

Table 1. Patients' characteristics

\begin{tabular}{lllll}
\hline Procedure & Number of cases & Sex & Median age & Age range \\
\hline Open & $\mathbf{2 5}$ & 20 Male: 5 Female & $\mathbf{7 0}$ & $\mathbf{4 4}$ to $\mathbf{8 5}$ \\
Right hemicolectomy & 7 & 4 Male: 3 Female & 77 & 44 to 84 \\
Left hemicolectomy & 1 & 1 Female & 72 & 72 \\
Hartman's & 1 & 1 Male & 69 & 69 \\
Subtotal colectomy & 2 & 1 Male: 2 Female & 82 & 82 \\
Anterior resection & 14 & 12 Male: 1 Female & 69 & 59 to 85 \\
Laparoscopic & $\mathbf{2 5}$ & $\mathbf{1 6}$ Male: 9 Female & $\mathbf{7 0}$ & $\mathbf{4 3}$ to $\mathbf{8 8}$ \\
Right hemicolectomy & 7 & 5 Male: 2 Female & 72 & 61 to 79 \\
Sigmoid colectomy & 5 & 2 Male: 3 Female & 70 & 62 to 79 \\
Anterior resection & 13 & 9 Male: 4 Female & 68 & 43 to 88 \\
\hline
\end{tabular}

Overall more patients in the laparoscopic received pre-operative down-staging therapy for rectal cancer compared to the open surgery group (Table 3 ). However this difference in patient distribution was not significant $(p=0.197)$. Laparoscopic surgery significantly yielded greater number of lymph nodes than open surgery in patients receiving pre-operative down-staging therapy $(p=0.008)$, however in patients without neo-adjuvant therapy the number of lymph nodes identified was not significantly raised $(p=0.25)$. In both the open and laparoscopic surgery groups pre-operative down-staging therapy decreased the median number of retrieved lymph nodes; the decrease was only significant in the open surgery group ( $p=0.01)$ vs. $(p=0.07)$ (Table 4$)$.

Table 2. Distribution of Dukes stage for each patient group

\begin{tabular}{|c|c|c|c|c|}
\hline \multirow[b]{2}{*}{ Procedure } & \multicolumn{4}{|c|}{ Dukes Classification (number of cases) } \\
\hline & $\mathbf{A}$ & $\mathbf{B}$ & C1 & $\mathrm{C} 2$ \\
\hline Open & 5 & 10 & 8 & 2 \\
\hline Right Hemicolectomy & 1 & 3 & 1 & 2 \\
\hline Left Hemicolectomy & 0 & 0 & 1 & 0 \\
\hline Hartman's & 0 & 0 & 1 & 0 \\
\hline Subtotal Colectomy & 0 & 1 & 1 & 0 \\
\hline Anterior Resection & 4 & 6 & 4 & 0 \\
\hline Laparoscopic & 9 & 11 & 3 & 2 \\
\hline Right Hemicolectomy & 1 & 4 & 1 & 1 \\
\hline Sigmoid Colectomy & 1 & 2 & 2 & 0 \\
\hline Anterior Resection & 7 & 5 & 0 & 1 \\
\hline
\end{tabular}


Table 3. Distribution of patients received pre-operative down-staging therapy

\begin{tabular}{llll}
\hline & Number of Patients & \\
\hline & Open & Laparoscopic \\
Chemo-Radiotherapy & 4 & 10 & \\
Radiotherapy & 1 & 0 & $P=0.179$ \\
Total & 5 & 10 & \\
\hline
\end{tabular}

Table 4. A comparison of median number of lymph nodes retrieved from open and laparoscopic surgical specimens from patients that have received pre-operative down-staging therapy versus patients who did not receive it.

\begin{tabular}{|c|c|c|c|}
\hline & \multicolumn{2}{|c|}{ Median Lymph Node Count } & \multirow[b]{3}{*}{$P=0.25$} \\
\hline & Open & Laparoscopic & \\
\hline No preoperative chemoradiotherapy & 17 ( $\mathrm{n}=20$ patients) & 18 ( $\mathrm{n}=15$ patients) & \\
\hline \multirow[t]{2}{*}{ Preoperative chemoradiotherapy } & 9 (n= 5 patients) & 14.5 ( $\mathrm{n}=10$ patients) & $P=0.008$ \\
\hline & $P=0.01$ & $P=0.07$ & \\
\hline
\end{tabular}

Laparoscopic surgery yielded greater median lymph node count than open surgery for right hemicolectomy and anterior resections. For all resections, the overall median lymph node count was equal for both open and laparoscopic groups (no. =16). There was no significant difference in lymph node retrieval between the two groups for all resections (Table 5).

Table 5. Median number of retrieved lymph nodes in different resections

\begin{tabular}{llll}
\hline & Median lymph node count & \\
\hline Procedure & Open & Laparoscopic & $P$ Value \\
Right hemicolectomy & 17 & 18 & 0.8 \\
Left hemicolectomy & 17 & N/A & N/A \\
Hartman's & 9 & N/A & N/A \\
Subtotal colectomy & 18.5 & N/A & N/A \\
Sigmoid colectomy & N/A & 17 & 0.65 \\
Anterior resection & 13.5 & 14 & 0.43 \\
All Resections & 16 & 16 & \\
\hline
\end{tabular}

\section{Discussion}

Improving the lymph node yield of patients with non-metastatic colorectal cancer is of major importance; as lymph node status is the strongest pathological predictor of patient outcome. Due to the high risk of tumor recurrence in lymph node positive disease ${ }^{[14]}$ inadequate lymph node sampling has dire consequences. It can lead to positive lymph nodes being missed and result in patients being inappropriately classified as having lymph node negative disease ${ }^{[15]}$. These patients may not receive the benefits of adjuvant therapy and latter develop local recurrence ${ }^{[14]}$.

Several previous studies have attempted to define the learning for learning curve for performing laparoscopic colorectal surgery; the studies have been based on surgeon and patient outcomes such as operative time, conversion rate, hospital stay duration and intraoperative and postoperative complications ${ }^{[2-5]}$. However, there has been controversy which outcome can be used as a proxy in the measurement of the ability of a surgeon to perform laparoscopic colorectal surgery ${ }^{[16]}$. Regardless of precise length of the learning curve, in this study we have examined the oncological safety of laparoscopic colorectal surgery compared to open surgery in the surgeon's first 25 unsupervised resections which is well below the length of most reported learning curves. By examining the lymph nodes of resections of the very early part of the learning curve and comparing them with open resections we have shown that laparoscopic colorectal surgery can yield equal numbers of lymph nodes for all resections. Even though there have been reported studies looking into the differences in patient and surgeon based outcomes during the learning process, there have been no reported studies looking into the number of retrieved lymph nodes in relation to the learning curve in laparoscopic colorectal surgery. In this study, there 
was no significant difference in lymph node yield during the initial learning curve. Furthermore the median lymph node count for all types of laparoscopic resections was above the recommended minimum of $12^{[17-18]}$.

In both the open and laparoscopic surgery groups the use of pre-operative down-staging therapy in rectal cancer decreased the median number of retrieved lymph nodes. This was similarly reported in other studies as it was found that both short course radiotherapy and long course chemo-radiotherapy given over several weeks have been shown to significantly reduce the size of mesorectal lymph nodes; making nodes harder to find or even reduce the number of lymph nodes detected within the specimen ${ }^{[19]}$. However, we noted that this reduction in the number of lymph nodes following the use of pre-operative down-staging therapy was only significant in the open surgery group. There was no significant difference between the numbers of retrieved lymph nodes in the laparoscopic group when we compared those who had pre-operative down-staging therapy with those who did not. This is an interesting observation; and to the best of our knowledge, has not been reported before. However, this observation should be interpreted with caution due to the small numbers in the subgroups which can make statistical analysis misleading. We are planning to conduct a further study to assess this observation with greater numbers in each subgroup.

Whilst there are many variables that may affect lymph node counts our study has the advantage of minimising most of them apart from the variable of interest which is the early learning phase of laparoscopic surgery. We looked into two comparable open \& laparoscopic groups of patients in terms of patients' age, Dukes staging, site of the primary \& resection type. Both the open and laparoscopic surgical specimens were evaluated in the same pathology department by the same group of pathologists following a standard pathology template; to ensure a consistent dissection and reporting style from all the pathologists in the department as data collected by SEER (Surveillance, Epidemiology, and End Results) has shown that the geographic location of lymph node assessment was a statistically significant predictor of adequate lymph node evaluation ${ }^{[20]}$.

We acknowledge that our study might have some limitations as it is retrospective. Also, it could be criticised because the total number of laparoscopic cases was only 25 cases and it included various types of colorectal resections. However, this design was made to ensure that the surgeon was still in the early phase of the learning curve and the number of retrieved lymph nodes reflected that. It could be argued that the study is rather limited as it only includes a single surgeon series. However, we believe that it is useful to look at the number of retrieved lymph nodes in colorectal cancer resections for individual surgeons. This study could initiate the interest to design another study to look at the relationship between the early phase of the learning curve and lymph node retrieval in laparoscopic colorectal cancer resections for multiple surgeons. This will aid to support the current view that laparoscopic surgery is oncologically as safe \& effective as open approach for colorectal malignancies.

\section{Conclusion}

Our study has explored the relationship between the number of retrieved lymph nodes in colorectal cancer resections and the learning curve of laparoscopic colorectal surgery compared to open practice of a single surgeon working with a single group of pathologists. Future multicentre study research may be needed to confirm if a similar learning curve is experienced by other surgeons during their initial laparoscopic colorectal surgery in other centres before generalising the findings in this study.

\section{Conflict of interest}

The author declares that there is no conflict of interest statement. 


\section{References}

[1] Jacobs, M, Verdeja JC, Goldstein HS. Minimally invasive colon resection (laparoscopic colectomy). Surgical Laparoscopy \& Endoscopy 1991;1(3):144-50. PMid:1688289

[2] Jayne DG., Guillou PJ, Thorpe H, Quirke P, Copeland J, Smith AMH, Heath RM,. Brown JM. Randomized Trial of Laparoscopic-Assisted Resection of Colorectal Carcinoma: 3-Year Results of the UK MRC CLASICC Trial Group. J Clin Oncol 2007;25(21):3061-68. PMid:17634484 http://dx.doi.org/10.1200/JCO.2006.09.7758

[3] Khaikin M, Bashankaev B, Person B, Cera S, Sands D, Weiss E, Nogueras J, Vernava A, Wexner SD. Laparoscopic versus open proctectomy for rectal cancer: patients' outcome and oncologic adequacy. Surg Laparosc Endosc Percutan Tech. 2009;19(2);118-22. http://dx.doi.org/10.1097/SLE.0b013e31819a66f5

[4] Veldkamp R, Kuhry E, Hop WCJ, Jeekel J, Kazemier G, Bonjer HJ, Haglind E. Laparoscopic surgery versus open surgery for colon cancer: short-term outcomes of a randomised trial. The Lancet Oncology 2005;6(7):477-84. http://dx.doi.org/10.1016/S1470-2045(05)70221-7

[5] Transatlantic laparoscopically assisted vs open colectomy trials study group. Laparoscopically assisted vs open colectomy for colon cancer: a meta-analysis. Arch Surg 2007;142(3):298-303. PMid:17372057

[6] Porter GA, Soskolne CL, Yakimets WW, Newman SC. Surgeon-related factors and outcome in rectal cancer. Annals of Surgery 1998;227(2):157-67. PMid:9488510 http://dx.doi.org/10.1097/00000658-199802000-00001

[7] Tekkis, PP, Senagore AJ, Delaney CP, Fazio VW. Evaluation of the learning curve in laparoscopic colorectal surgery: comparison of right-sided and left-sided resections. Annals of Surgery 2005;242(1):83-91. PMid:15973105 http://dx.doi.org/10.1097/01.sla.0000167857.14690.68

[8] Wishner JD, Baker JW, Hoffman GC, et al. Laparoscopic-assisted colectomy. The learning curve. Surg Endosc 1995; 9(11):1179-83. PMid:8553229 http://dx.doi.org/10.1007/BF00210923

[9] Li G, Yan H, Yu J, et al. Learning curve of laparoscopic resection for rectal cancer. Nan Fang Yi Ke Da Xue Xue Bao 2006;26(4):535-38. (English abstract. Original article in Chinese) PMid:16624777

[10] Schlachta CM, Mamazza J, Seshadri PA, et al. Defining a learning curve for laparoscopic colorectal resections. Dis Colon Rectum 2001;44(2):217-22. http://dx.doi.org/10.1007/BF02234296

[11] Psaila, J, Bulley SH, Ewings P, Sheffield JP, Kennedy RH. Outcome following laparoscopic resection for colorectal cancer. BJS 1998;85(5):662-4. PMid:9635817 http://dx.doi.org/10.1046/j.1365-2168.1998.00634.x

[12] Royal College of Pathologists. Minimum dataset for colorectal cancer histopathology reports. The Royal College of Pathologists, 1998.

[13] Royal College of Pathologists. Dataset for colorectal cancer (2nd edition). The Royal College of Pathologists, 2007.

[14] Chau I. \& Cunningham D. Adjuvant therapy in colon cancer: current status and future directions. Cancer Treatment Reviews 2002; 28(5):223-36. http://dx.doi.org/10.1016/S0305-7372(02)00047-6

[15] Joseph NE., Sigurdson ER, Hanlon AL, Wang H, Mayer RJ, MacDonald JS, Catalano PJ, Haller DG. Accuracy of determining nodal negativity in colorectal cancer on the basis of the number of nodes retrieved on resection. Ann Surg Oncol 2003;10(3):213-18. PMid:12679304 http://dx.doi.org/10.1245/ASO.2003.03.059

[16] Chen W, Sailhamer E, Berger DL, Rattner DW. Operative time is a poor surrogate for the learning curve in laparoscopic colorectal surgery. Surgical Endoscopy 2007;21(2):238-43. PMid:17180745 http://dx.doi.org/10.1007/s00464-006-0120-6

[17] Sobin L H, Greene FL. TNM classification: clarification of number of regional lymph nodes for pNo. Cancer $2007 ; 92$, (2): 452. http://dx.doi.org/10.1002/1097-0142(20010715)92:2<452::AID-CNCR1342>3.0.CO;2-B

[18] Nelson H, Petrelli N, Carlin A, Couture J, Fleshman J, Guillem J, Miedema B, Ota D, Sargent D. Guidelines for colon and rectal cancer surgery. J. Natl. Cancer Inst. 2001;93(8):583-96. http://dx.doi.org/10.1093/jnci/93.8.583

[19] Scott, N., Thorne C, Jayne D. Lymph node retrieval after neoadjuvant radiotherapy for rectal adenocarcinoma. Journal of Clinical Pathology 2004;57(3):335-36. PMid:14990616 http://dx.doi.org/10.1136/jcp.2003.013441

[20] Baxter N N., Virnig DJ, Rothenberger D, Morris A, Jessurun J, Virnig BA. Lymph Node Evaluation in Colorectal Cancer Patients: A Population-Based Study. J. Natl. Cancer Inst. 2005;97(3):219-25. PMid:15687365 http://dx.doi.org/10.1093/jnci/dji020 